\title{
O CONSELHO ESCOLAR E A IMPLEMENTAÇÃO NO MUNICÍPIO DE CASCAVEL-
} PR

\author{
CAROZZI, Elizangela S. ${ }^{1}$ \\ ESTRADA, Adrian A. ${ }^{2}$
}

\section{RESUMO:}

Este trabalho tem por objetivo apresentar uma síntese da produção realizada na dissertação de mestrado intitulada "Organização e Gestão Escolar: uma análise do Conselho Escolar na rede pública municipal de Cascavel"3. A pesquisa teve por objetivo principal apresentar uma análise do processo de implementação do Conselho Escolar no município de Cascavel no ano de 2012. O Conselho Escolar faz parte do Programa Nacional de Fortalecimento dos Conselhos Escolares (PNFCE), criado em 2004 na primeira gestão do então presidente Luiz Inácio Lula da Silva. Esse programa proclama fomentar a gestão democrática por meio da participação da comunidade escolar e, para isso, oferta cursos de formação para o desempenho do papel de conselheiro. Entendendo que é um programa direcionado por meio de políticas públicas e não por um movimento que emergiu da sociedade, o estudo buscou refletir sobre os limites e as possibilidades da participação da comunidade escolar na gestão da escola pública a partir de um instrumento que é o Conselho Escolar. Assim, para o desenvolvimento do trabalho realizou-se uma pesquisa bibliográfica, com análise de documentos e com pesquisa de campo realizada por meio de entrevistas e de questionários com diretores das escolas municipais, com demais membros do Conselho Escolar, para entendimento do objeto de pesquisa participamos ainda de observações em Seminários, cursos de formação para conselheiros e reunião do Conselho Escolar. Nossa preocupação é resgatar as questões da pesquisa e apontar os limites e possibilidades de um Conselho Escolar dentro de uma gestão na escola pública do campo de pesquisa, recuperando aspectos fundamentais da participação da comunidade.

PALAVRAS CHAVE: Conselho Escolar; gestão democrática; participação.

\footnotetext{
${ }_{1}^{1}$ Graduada em Pedagogia pela Universidade Estadual do Oeste do Paraná - UNIOESTE, Campus de Cascavel, mestrado em Educação pela mesma universidade, área de concentração: Sociedade, Estado e Educação. Membro do Grupo de Pesquisa em Gestão Escolar - GPGE.

${ }^{2}$ Doutor em Educação pela USP; Professor do Colegiado de Pedagogia e do Mestrado em Educação da Universidade Estadual do Oeste do Paraná - UNIOESTE, Campus de Cascavel.

${ }^{3}$ Dissertação de mestrado defendida no ano de 2015 na Universidade Estadual do Oeste do Paraná - UNIOESTE Programa de Pós-Graduação em Educação, sob a orientação do Prof. Dr. Adrian Alvarez Estrada.
} 


\begin{abstract}
This paper is aimed to present a summary of the production carried out in Master's Degree dissertation entitled "Organization and School Management: an analysis of the School Council implemented in the city of Cascavel". That research has had as its main goal to present an analysis of the School Council's implementation process in the city of Cascavel, in 2012. The School Council, is part of the National Programme of School Councils Strengthening (PNFCE) which was created in 2004 during the first Luiz Inácio Lula da Silva's government. This programme proclaims to promote the democratic management through the school community participation, for this, the programme offers education courses for the role performed by counsellor. Understanding that it is a programme guided by public policies and it's not a movement which emerged from society, this study tries to reflect about the limit and the possibilities of the school community participation in a democratic management through an instrument which is the School Council. Hence, to develop this job, it was made a bibliographical research, a documental analysis and a field research through interviews and questionnaires with public municipal schools' principals, and with others School Council's members. In order to understand the research object, it was made some observations in Seminaries, education courses for counsellors and School Councils meetings. Our solicitude is to rescue the research questions and to put forward the limit and the possibilities of a School Council inside of a public school of the research field, recovering essential aspects of the community participation.
\end{abstract}

KEY-WORDS: School Council. Democratic Management. Participation

\title{
INTRODUÇÃO:
}

Este artigo tem por objetivo apresentar um estudo realizado referente ao processo de implementação do Conselho Escolar no município de Cascavel - PR. Nosso objeto de análise que é o Conselho Escolar foi instituído com o objetivo de ser um instrumento de gestão democrática na escola pública brasileira.

A escola brasileira, de modo geral, é alvo de críticas devido à suposta dificuldade de alcançar os seus objetivos. Nesse sentido, apresentam-se justificativas e emergem novas propostas para orientar a gestão, com objetivo de a administração refletir sobre seu modo de fazer e ampliar sua “competência profissional” (LÜCK, 2009).

Entretanto, é necessário um olhar mais amplo e claro da real situação da gestão na instituição escolar, que considere os determinantes que abrangem os aspectos políticos, econômicos e sociais que refletem no desenvolvimento do trabalho na gestão da escola. 
Assim, adquire especial relevância a investigação da implantação do Conselho Escolar que proclama a "gestão democrática do ensino público e a melhoria da qualidade do ensino" (CASCAVEL, 2012).

Ao analisarmos a gestão da escola pública do município de Cascavel, de modo particular o Conselho Escolar, propalado como instrumento de gestão democrática, a questão que nos intriga é: como se tem desenvolvido a participação da comunidade no Conselho Escolar?

A prática democrática no ambiente escolar demanda uma compreensão de qual democracia se pretende exercer na gestão da escola, para que, em última instância, não seja reduzida em mera representação simbólica.

Diante das questões apresentadas, o percurso metodológico iniciou-se com a definição das fontes bibliográficas, as quais oferecem esclarecimentos que corroboraram com a análise crítica da categoria central da nossa pesquisa, que é a participação, além da análise de documentos e dos dados coletados da pesquisa de campo.

Os Conselhos Escolares emergem em um contexto de redemocratização do país, em que o foco era a luta por espaços de participação da sociedade na gestão das escolas públicas. Nossa intenção é discutir como se estabelece a gestão democrática por meio de um colegiado com a responsabilidade de envolver a comunidade na gestão da escola.

É preciso constatar em quais condições essa participação tem se realizado no município de Cascavel, via Conselho Escolar, sob o amparo do Programa Nacional de Fortalecimento dos Conselhos Escolares (PNFCE), programa lançado em 2004, no primeiro governo de Luiz Inácio Lula da Silva (2003-2006). Esse programa é reconhecido legalmente por meio da Portaria Ministerial n 2.896/2004, sendo a Secretaria de Educação Básica responsável pela execução. O documento do programa anuncia: "[...] ampliar a participação das comunidades escolar e local na gestão administrativa, financeira e pedagógica das escolas públicas [...]" (BRASIL, 2004, s/p). Além disso, conta com a participação de organismos nacionais e internacionais, tais como Banco Mundial na qual o trabalho é "[...] discutir, analisar e propor medidas para sua implementação [...]" (BRASIL, 2004, s/p).

A Lei $n^{0}$ 6.116/2012, que regulamenta o Conselho Escolar no município de Cascavel, esclarece a finalidade do colegiado, tendo como papel "[...] efetivar a gestão democrática, atuando como mediador dos anseios da comunidade escolar, buscando alternativas para efetivar as políticas educacionais que visam garantir o cumprimento da função de educar e cuidar" 
(CASCAVEL, 2012, s/p). A referida Lei apresenta como atribuições do Conselho Escolar as funções Deliberativa, Consultiva, Fiscalizadora e Mobilizadora.

A preocupação que permeou a pesquisa foi ir além das aparências e observar a realidade escolar de forma que pudéssemos compreender a totalidade e as contradições das relações sociais que envolvem o objeto de pesquisa e os seus sujeitos.

\section{Conselhos Escolares}

O Conselho Escolar é um órgão colegiado que possui como proposta a participação da comunidade na gestão da escola, com a perspectiva de divisão de poder na tomada de decisões na instituição e na melhoria da qualidade da educação.

É imprescindível conhecer seus fundamentos e o significado do conselho na gestão da educação e, para isso, é importante sua contextualização histórica que permita a melhor compreensão dos seus limites, das suas possibilidades e contradições dentro da sociedade capitalista.

Em sua origem etimológica, o termo Conselho:

[...] vem do latim Consilium. Por sua vez, consilium provém do verbo consulo/consulere, significando tanto ouvir alguém quanto submeter algo a uma deliberação de alguém, após uma ponderação refletida, prudente e de bom-senso. Trata-se, pois, de um verbo cujos significados postulam a via de mão dupla: ouvir e ser ouvido. Obviamente a recíproca audição se compõe com o ver e ser visto e, assim sendo, quando um Conselho participa dos destinos de uma sociedade ou de partes destes, o próprio verbo consulere já contém um princípio de publicidade (CURY, 2000, p. 47).

A história dos conselhos emergiu inicialmente com o objetivo de incutir a participação dos mais variados grupos sociais no poder. Embora não se tenha uma data precisa, é possível afirmar que a sua origem se confunde com a história da política e da democracia. Os registros históricos apontam para o povo hebreu com a institucionalização de formas primitivas e originais de gestão dos grupos sociais. A Bíblia registra a reunião de 70 anciãos ou sábios com objetivo de governo do povo, conhecido como "conselhos de anciãos" (BRASIL, 2004, s/p). 
Podemos observar que os conselhos, originalmente, eram compostos por uma coletividade seleta:

Os conselhos de anciãos das comunidades primitivas, que se fundavam no princípio da sabedoria e do respeito advindos da virtude, foram sendo gradativamente substituídos, nos Estados-nacionais, por conselhos de "beneméritos", ou "notáveis", assumindo caráter tecnocrático de assessoria especializada no núcleo de poder dos governos. O critério de escolha - dos mais "sábios", dos "melhores", dos "homens bons" - que fluía do respeito, da liderança na comunidade local, passa, gradativamente, a ser substituído pelo poder de influência, seja intelectual, econômico ou militar (BRASIL, 2004, p.16).

Um marco na história dos conselhos foi a

[...] forma de organização representativa do poder político na cidadeEstado, viriam a ganhar sua máxima expressão na Comuna Italiana, instituída a partir do século X. [...] Na medida em que a comuna se ampliou e outras categorias sociais passaram a integrá-la, surgiu a comuna popular (commune populi) que, adotando a democracia representativa e não mais direta como na comuna tradicional. $\mathrm{Na}$ administração das cidades a Itália adota até os dias atuais a figura do Conselho Comunal (Consiglio Comunale), similar às nossas câmaras de vereadores, mas com mecanismos de escolha e eleição das listas de conselheiros que envolvem forte participação da comunidade. A gestão da comunidade local por meio de um conselho, constituído como representação da vontade popular, viria a encontrar sua expressão mais radical na Comuna de Paris, em 1871. Embora com duração de apenas dois meses, viria a constituir-se na mais marcante experiência de autogestão de uma comunidade urbana, perpetuando-se como um símbolo (BRASIL, 2004, p. 17).

A Comuna se ampliou, passando a ser integrada por outras categorias sociais e a adotar a democracia representativa, e não mais direta, com Comuna tradicional (BRASIL, 2004).

Assim, na primeira metade do século XX, a compreensão dos conselhos como instâncias populares passa a ser disseminada lentamente a grupos sociais identificados no ambiente de trabalho, conforme é apontado no Dicionário de Política:

Por Conselhos operários se entendem, segundo o significado literal da expressão, os organismos representativos colegiais que reproduzem as 
características formais do "conselho" como órgão de poder revolucionário; [...] Levado em conta o significado original da noção de "conselho" e a sua composição operária, o termo refere-se, pois, em primeiro lugar, a um fenômeno histórico definido, que coincide substancialmente com o ciclo de lutas operárias iniciado em 1915-16 nos principais centros industriais da Europa e transformado em aberto conflito político durante a crise revolucionária do primeiro pós-guerra (BOBBIO, 1998, p. 235).

Salienta-se, ainda, que os Conselhos populares tinham como objetivo resolver os conflitos era a voz da classe que representavam seja, "[...] nas cidades-Estado grecoromanas, nas comunas italianas e de Paris, ou na fábrica da era industrial” (BRASIL, 2004, p.18).

É importante assinalar que, apesar de ser reconhecido por grupos diferenciados, tal fato não significou a dissolução do caráter contraditório na constituição histórica do Conselho. Assim,

[...] a princípio os conselhos eram instâncias pensadas para o favorecimento da governabilidade por grupos seletos; posteriormente, os conselhos foram apropriados pelos grupos de esquerda como instâncias de caráter descentralizador do poder em prol das bandeiras populares. Tal contradição se manteve ainda que sutilmente e, apesar de a elite ter estrategicamente relativizado em seu discurso a tendência elitista que poderia ter um conselho, passou a incorporar o seu potencial descentralizador, mas sob uma vertente liberalizante-democrática (RAMOS; FERNANDES, 2010, p. 48).

No Brasil, como já descrevemos, os Conselhos emergiram em um contexto de

[...] redemocratização do país, na década de 1980, os movimentos associativos populares passaram a reclamar participação na gestão pública. O desejo de participação comunitária se inseriu nos debates da Constituinte, que geraram, posteriormente, a institucionalização dos conselhos gestores de políticas públicas no Brasil. Esses conselhos têm um caráter nitidamente de ação política e aliam o saber letrado com o saber popular, por meio da representação das categorias sociais de base. São muitas as formas de organização e as funções atribuídas a esses conselhos, mas sua origem radica sempre no desejo de participação na formulação e na gestão das políticas públicas (BRASIL, 2004, p.19). 
É fundamental ter em mente que Conselho é formado por um corpo, em que seus membros, com responsabilidades comuns, esforçam-se na busca de dialogar coletivamente referente aos problemas próprios da instituição que representam.

Esse corpo, no qual o Conselho Escolar faz parte, é denominado como um instrumento de gestão democrática, sendo que essa nova forma de administrar a instituição escolar pública constitui-se como uma ação coletiva. Essa nova proposta proclama uma organização social mais democrática, mais justa, pautada na inclusão de todos os segmentos da comunidade.

Dessa forma, é fundamental considerar que o Conselho Escolar é um espaço destinado à discussão e à construção comunitária, ou seja, é a voz de representantes da comunidade escolar, para isso, é imprescindível o comprometimento político (WERLE, 2003).

Os Conselhos Escolares provocaram esperanças de realização de relações democráticas dentro da instituição escolar. Conforme Paro (2001), entretanto, essas questões ainda estão longe de serem realizadas, tendo em vista que vivemos em uma sociedade capitalista, enraizada em relações de poder.

Contudo, não há como negar que um passo foi dado na abertura de espaços que possibilitam, no mínimo, um diálogo da comunidade com a gestão da escola pública.

Nesse sentido, a gestão deixa de ser uma prerrogativa de uma única pessoa e passa a se desenvolver em um trabalho coletivo, na pluralidade dos segmentos que compõem a comunidade escolar. Nessa perspectiva, divide-se o poder e a responsabilidade.

Entretanto, essa conquista trouxe, também, alguns temores e dúvidas por parte da direção da escola, já que o Conselho Escolar poderia representar a possibilidade de questionamentos de sua autoridade, ou até mesmo a discordância da comunidade em assuntos diversos (PARO, 2001).

Esses temores não ganharam força, uma vez que não podiam perder o que nunca tiveram, ou seja, "o poder de dirigir, com a autonomia que desejariam a unidade escolar" (PARO, 2001, p.79).

Essa atitude de temor dos dirigentes escolares está relacionada ao contexto histórico na qual a escola pública foi alicerçada, às relações de poder e ao autoritarismo na gestão da escola, reflexo de uma organização nos moldes de uma Administração Científica que foi constituída na instituição escolar e enraizada na prática diária que, infelizmente, ainda possui resquícios dentro 
de algumas escolas, dificultando, sobremaneira, o processo de envolvimento da comunidade escolar.

Em linhas gerais, Paro (2001) afirma que uma questão importante a ser discutida é o fato de que o Conselho Escolar tem sido um órgão isolado dentro da instituição escolar, além de estar revelando-se mais burocrático do que democrático.

Isso fica evidente quando o Conselho Escolar assume o papel de legitimador das questões previamente decididas por instâncias superiores.

O Conselho Escolar representa um espaço importante para a luta daqueles que fazem parte da comunidade escolar. Embora carregada de contradições e de conflitos, é necessário um esforço conjunto para a realização de uma educação de qualidade, comprometida com o sujeito histórico, já que a escola precisa "[...] se configurar democrática em suas ações como agência prestadora de serviços que precisa levar em conta os interesses dos usuários, a quem ela deve servir e para os quais foi criada" (PARO, 2001, p.81).

É no Conselho Escolar que os problemas relacionados à gestão da escola são apresentados e as reivindicações precisam ser discutidas e encaminhadas, além disso, se possível, as resoluções devem ser colocadas em prática. É nesse entendimento que o colegiado possui um papel político de grande importância, pois conta com a contribuição daqueles que atuam no Conselho.

Vale ressaltar que é importante ter clareza sobre o fato de que é essencial que ocorra decisões coletivas, embasadas por discussões, que possam garantir, democraticamente, que a comunidade escolar tenha a oportunidade de contribuir para a solução de problemas que envolvem não só suas vidas, mas, efetivamente, a vida de seus filhos, a começar por problemas enfrentados no cotidiano da vida escolar, estimulando, dessa forma, a compreensão de coletividade aos alunos.

O Conselho Escolar precisa refletir a vontade e o compromisso político que a escola tem com a educação, uma educação voltada para a transformação social e que não esteja alicerçada e administrada por princípios da Administração Geral (ANTUNES, 2002).

\section{O processo de democratização da gestão escolar}


O processo de abertura democrática realizada no Brasil, nos anos de 1980, foi um marco para nossa história, estando ligado a amplas discussões que repercutiram na organização da gestão das escolas públicas.

Para falar sobre o processo de democratização da gestão é importante compreender o contexto caracterizado pelo fim da ditadura civil-militar, do regime autoritário, da abertura política e da perspectiva de democratização.

É nessa perspectiva que Cunha (1991) aborda a questão da democracia em nosso país, como resultado do processo histórico autoritário, que culminou com a queda da Ditadura civilmilitar que ocorrera entre 1964 a 1985. Conforme o autor:

Tratar de democracia no Brasil é uma atividade que remete mais ao plano das esperanças do que das realizações. Com efeito, quando é que podemos dizer que houve um regime verdadeiramente democrático no Brasil? (CUNHA, 1991, p.19).

Antes de falar da luta pela democracia é importante apresentar uma definição do termo de democracia, entendida como um "[...] conjunto de regras de procedimentos para a formação de decisões coletivas, em que está prevista e facilitada a participação mais ampla possível dos interessados" (BOBBIO, 2000, p. 22).

$\mathrm{O}$ autor ainda esclarece duas concepções importantes que norteiam o pensamento sobre a democracia, ou seja, apresenta a democracia representativa que "[...] significa genericamente que as deliberações coletivas, isto é, as deliberações que dizem respeito à coletividade inteira, são tomadas não diretamente por aqueles que dela fazem parte, mas por pessoas eleitas para esta finalidade" (BOBBIO, 2000, p. 56). O autor apresenta, inclusive, a democracia direta, no sentido próprio da palavra, que quer dizer que "[...] o indivíduo participa ele mesmo nas deliberações que dizem respeito, é preciso que entre os indivíduos deliberantes e a deliberação que lhe diz respeito não exista nenhum intermediário" (BOBBIO, 2000, p. 63).

A concepção de democracia na sociedade contemporânea apresenta, entre outras, a expressão da democracia representativa. Assim:

A democracia representativa, também denominada democracia indireta por se concretizar pela via da representação não tem sido muito aceita 
por aqueles que apregoam a democracia substantiva. A alegação é que ser representado ou representar não atende as múltiplas determinações dos representados e tem frustrado expectativas em relação a buscar e a legitimar os meios que venham a possibilitar as intervenções nas ações governamentais, em qualquer nível, inclusive quando a discussão versa sobre a educação (ARANDA, 2009, p.75).

Para Dias (2007), a democracia representativa, ou indireta, tem sido insuficiente para atender à demanda na sociedade contemporânea, ou seja, para captar as exigências sociais e transformá-las em decisões políticas. Dessa forma, enfatiza que,

[...] a democracia participativa caracterizada pela intervenção popular no planejamento, na deliberação, no exercício ou na fiscalização da atuação governamental, ou ainda na formação da vontade legiferante do Estado, por meio de canais formais de participação (DIAS, 2007, p. 45).

Sob essa perspectiva, Dias (2007) esclarece que o apoio ao regime democrático tem se manifestado de forma insatisfatória devido à atuação governamental. Na Constituição de 1988, devido à pressão da sociedade, foram introduzidos instrumentos de participação popular, a exemplo do Conselho Escolar, objeto de nossa pesquisa, porém, "[...] as formalidades constitucionais não se converteram, contudo, em instrumentos de atuação popular” (DIAS, 2007, p. 46).

Bobbio (2000) critica as práticas educacionais populares intituladas de democráticas, asseverando que não correspondem às formas de sociabilidade de poder, pois, geralmente, as decisões são absorvidas pela burocracia. Sobre o Conselho Escolar, o autor o aponta como parte de uma reforma democrática, considerada insuficiente e acrescenta, ainda, que "a participação multidirecional tem o seu reverso da medalha, que é a apatia política" (BOBBIO, 2000, p. 69). Para o autor, as práticas educacionais democráticas funcionam como meio de pressão, entretanto, não chegam a novas formas de socialização do poder.

Pode-se apreender, portanto, que a participação é o princípio basal da democracia. Se não houver pleno exercício da participação, a democracia não se desenvolve em sua totalidade. Dessa forma, a articulação entre ambas é fundamental, ademais, vale lembrar que ambas dependem de outros princípios como igualdade política, condições econômicas e sociais, justiça 
e liberdade para que possam realizar uma participação real. Uma participação em que os sujeitos possam tomar parte na construção da sociedade em que estão inseridos (BORDENAVE, 1994).

Para Bordenave (1994) a participação precisa ser aprendida, visto que é uma habilidade que não é inata, apesar de ser uma necessidade básica do ser humano.

Dessa forma, compreendemos ser fundamental o estímulo, o debate que reflita a prática da participação, já que compreendemos que o Conselho Escolar pode ser uma possibilidade de abertura e de envolvimento dos segmentos que compõem a comunidade escolar.

Sob esse aspecto, fica claro que é fundamental a participação nas decisões que envolvem questões que podem, verdadeiramente, influenciar nos rumos da educação, e não somente uma participação meramente ilustrativa para legitimar os ideais já estabelecidos.

A gestão democrática na educação tem como ponto de partida os movimentos sociais impulsionados pela luta pelos direitos à participação, como já comentamos. Entretanto, nos encaminhamentos políticos dos anos de 1990, suas raízes foram firmadas em princípios autoritários e de influência da administração capitalista vinculada a uma lógica de produção e de eficiência.

Em linhas gerais, Lima (2004) esclarece que:

Os aspectos que marcaram a concepção de "democratização" na década de 1980 estão ligados especialmente à perspectiva de redemocratização do Estado brasileiro que, no início daquela década, viu instituída a abertura política, a distensão do regime autoritário, após a derrocada do modelo econômico, que se somou ao conclamo popular organizado em defesa de eleições diretas e de formas de participação da sociedade civil organizada no controle dos governos, ou seja, a democratização em seus aspectos sociais, políticos e econômicos (LIMA, 2004, p. 17).

No campo educacional tal processo resultou, dentre outras ações, na criação de Conselhos Deliberativos, que passaram a ter um papel central na gestão da escola, com o intuito de atenuar os aspectos coercitivos da administração. Esse processo ocorreu de forma variada dentro do país, ou seja, sua implantação se deu conforme a organização de cada estado e município (ANTUNES, 2002).

Lima (2004) corrobora com a posição de Antunes (2002) apontando que a década de 1980 foi também marcada por inúmeras greves, insuflamento à participação e, na área 
educacional, essas ações refletiram na reativação dos grêmios estudantis livres ${ }^{4}$ e do Conselho Escolar ${ }^{5}$. Nesse sentido, “[...] passou a compor o organograma da escola como instituição deliberativa; alguns estados implementaram as eleições de diretores” (LIMA, 2004, p. 18).

O Conselho faz parte do processo de uma gestão democrática por meio da participação popular, é fruto de movimentos sociais de propostas de oposição ao regime autoritário. De acordo com GOHN (2002), “a discussão sobre os conselhos populares nos anos 1980 tinha como núcleo a questão da participação popular" (GOHN, 2002, p. 11). Assim, fruto de reivindicações populares contra o regime militar, o Conselho Escolar, nesse período, reflete a participação da população que fora legitimada de forma tímida pela Constituição Federal de 1988.

Como resultado dessas ações, foi percorrido um caminho complexo de lutas para a legitimação da gestão democrática do ensino público em forma de lei, a LDBEN - Lei de Diretrizes e Bases da Educação Nacional, a Lei n ${ }^{0}$ 9.394/96, o Plano Nacional de Educação e a Lei n ${ }^{\circ}$ 13.005/2014 PNE - 2014/2024, que aponta, como desafio, a superação das desigualdades, a valorização dos profissionais da área incluindo, ainda, a gestão democrática.

O marco legal da gestão democrática, como um dos princípios que devem nortear o ensino público, está firmado na Constituição Federal de 1988, “art. 206; IV gestão democrática do ensino público na forma da lei" (BRASIL, 1988, s/p). O princípio de gestão democrática foi afirmado no documento como uma conquista. No entanto, o que se observa é que sofreu restrições ao limitar-se ao ensino público, visto que não se estendeu ao ensino privado (PARO, 2001).

A Lei n ${ }^{0}$ 9394/96 apresenta, ainda, alguns parâmetros em relação à gestão democrática:

Art. 14. Os sistemas de ensino definirão as normas da gestão democrática do ensino público na educação básica, de acordo com as suas peculiaridades e conforme os seguintes princípios:

I - participação dos profissionais da educação na elaboração do projeto pedagógico da escola;

II - participação das comunidades escolar e local em conselhos escolares ou equivalentes (BRASIL, 1996, s/p).

\footnotetext{
${ }^{4}$ O grêmio estudantil, como qualquer outra manifestação liderada pelo movimento dos estudantes, ficou proibido com o golpe de 64. O retorno dos Grêmios Estudantis ocorre oficialmente em outubro de 1985, com a promulgação da Lei Federal n ${ }^{\circ} 7398 / 85$, denominada Lei do Grêmio Livre, a expressão "livre" refere-se à possibilidade de organização estudantil, após um período de perseguição.

${ }^{5}$ Lima (1995) indica que os Conselhos Escolares deliberativos no Estado de São Paulo iniciaram por meio da Lei Complementar $n^{0}$ 444/1985. A denominação Conselho Escolar ocorre nas Escolas Estaduais de São Paulo pelo Decreto $\mathrm{n}^{\circ} 11.625 / 78$, com caráter consultivo.
} 
A legislação pertinente determina algumas direções para a gestão democrática como a participação da comunidade escolar, mas não esclarece a questão, ou seja, a forma como ocorrerá a participação nos processos decisórios, relegando, dessa forma, para os estados e para municípios, a definição de normas de orientação, “[...] cujos governos poderão ou não estar articulados com interesses democráticos" (PARO, 2001, p.55).

A partir dos documentos legais nacionais, os governos formulam e constituem normas próprias, cujo objetivo se pauta na gestão democrática nas escolas públicas. Contudo, o que ocorre pela falta de normas claras é o desenvolvimento de formas variadas de “[...] gestão democrática, gestão participativa, gestão compartilhada, co-gestão, dentre outras [...] (GRACINDO, 2009, p. 136).

Uma visão predominantemente econômica da gestão está ligada ao sinônimo de gerência e principalmente ao referencial mercadológico, cujo financiamento conta com a participação de organismos internacionais. Acrescenta-se, ainda, que essa prática, muitas vezes denominada de “neutra”, reforça a manutenção da sociedade vigente (GRACINDO, 2009).

A proposta de Lei mais recente sobre o tema é o Projeto de Lei no $2384 / 11$, da deputada Fátima Bezerra (PT-RN), que propõe a alteração da Lei de Diretrizes e Bases da Educação LDB - Lei n 9.394/1996, dispondo sobre a gestão democrática nas escolas. O projeto prevê a participação dos conselheiros escolares na elaboração do projeto pedagógico das escolas públicas de ensino básico, com o objetivo de acompanhar e de avaliar sua execução, inclusive sob os aspectos administrativos e financeiros. O projeto estabelece, também, que a atuação no Conselho Escolar será considerada um serviço público de grande relevância cuja formação consiste na inclusão da comunidade escolar e local.

Na justificativa do projeto, Fátima Bezerra esclarece que o Conselho Escolar é um órgão colegiado de grande importância para a prática da democracia. A sua proposta é delegar ao Conselho Escolar a função deliberativa, consultiva, fiscalizadora, mobilizadora e pedagógica, além, é claro, da elaboração do projeto político pedagógico. Ainda, de acordo com o projeto, leis específicas deverão ser definidas pelo Distrito Federal, pelos Estados e pelos Municípios no que se refere à sua composição e à eleição de seus membros. Cabendo, dessa forma, ao regimento interno da escola definir a orientação do funcionamento do Conselho Escolar. 
Atualmente, o Projeto de Lei n ${ }^{\circ}$ 2384/2011, proposto pela Deputada Federal Fátima Bezerra, está aguardando retorno do Senado Federal, tendo em vista que está sujeito à apreciação conclusiva. O projeto será examinado pelas comissões de Educação e Cultura, de Constituição e Justiça e de Cidadania.

A respeito do assunto, Fátima Bezerra ainda assevera que:

A escola é um espaço enriquecedor, adequado para a prática do ensino, aprendizagem e vivência de valores. Nela os indivíduos se socializam, brincam e experimentam a convivência com a diversidade humana. Pensando assim, o Conselho Escolar pode ser vital para o exercício da democracia participativa. A implementação deste colegiado nas escolas sustentará em nível social ampliado dois pilares fundamentais das sociedades contemporâneas: democracia e cidadania (BEZERRA, 2011, $\mathrm{s} / \mathrm{p})^{6}$.

Por tais razões, podemos compreender que, no Brasil, a democracia, exercida por meio da participação em órgãos colegiados, como instrumentos que oportunizam voz aos membros da instituição escolar, ainda está sendo estabelecida.

É por meio desses marcos legais que o "Conselho Escolar" se institui como um instrumento de participação no meio educacional, ou seja, como um órgão colegiado que tem por finalidade a articulação entre os segmentos da comunidade escolar. O marco legal é só um primeiro passo em direção ao modo de organizar-se e de atender a objetivos e a finalidades em um processo democrático na gestão da escola pública.

A luta pela democratização da educação tem sido uma bandeira dos movimentos sociais no Brasil. Acompanhando a história, podemos verificar movimentos da sociedade civil promovendo inúmeras reivindicações em prol da ampliação do atendimento educacional. Dessa forma, o Estado vem atendendo, de forma tímida, as reivindicações que estão longe da universalização esperada (GRACINDO, 2007).

\section{Programa Nacional de Fortalecimento dos Conselhos Escolares - PNFCE}

\footnotetext{
${ }^{6}$ Disponível em: http://www2.camara.leg.br/. Acesso em: 12 mar. 2014.
} 
O programa anuncia colaborar com o sistema de ensino para a implantação e o fortalecimento dos Conselhos Escolares nas escolas públicas de ensino básico. Além disso, tem o intuito de construir, de promover e de qualificar uma política de gestão democrática, tendo como alvo: ampliar a participação da comunidade, promover a capacitação dos conselheiros que já atuam e estimular a construção coletiva de um projeto educacional (BRASIL, 2004).

Em linhas gerais, o Programa divulga o propósito de oferecer subsídios para aprimorar e implantar a gestão democrática envolvendo a comunidade escolar. Para a realização dessa tarefa, tem como parceiro as organizações nacionais e internacionais, como já apontamos. As organizações que estão envolvidas são:

União Nacional dos Dirigentes Municipais de Educação (Undime); Confederação Nacional dos Trabalhadores em Educação (CNTE); Fundo das Nações Unidas para a Infância (Unicef); Organização das Nações Unidas para a Educação, a Ciência e a Cultura (Unesco); Programa das Nações Unidas para o Desenvolvimento (PNUD) (BRASIL, 2004, s/p).

As propostas reforçam o incentivo à participação da comunidade na gestão da escola, que resulta no viés do PNFCE, que é a participação. Para tal ação, inicialmente, constituiu-se a promoção de seminários, ou seja, encontros com o intuito de fomentar o envolvimento dos técnicos, dos profissionais da educação e dos membros da comunidade escolar na implantação e no fortalecimento dos Conselhos Escolares. Esses encontros foram organizados em regime de colaboração entre as redes públicas de ensino: federal, estadual e municipal.

O Programa compõe um conjunto de ações de estratégia política educacional do Governo de Luiz Inácio Lula da Silva. O Plano de governo no primeiro mandato aponta a necessidade de investimento na educação, afirmando que:

[...] investir eficientemente no ensino, ampliando o acesso das crianças à escola. É vital recuperar a rede pública, tanto no nível fundamental quanto no médio e nas universidades, valorizando principalmente a qualidade. Uma boa formação da juventude colabora para a retomada do desenvolvimento sustentável, além de ser um diferencial para a competição do País no mercado internacional. A educação de qualidade é fator de emancipação e cidadania, contribui para que os jovens se integrem ao mercado de trabalho e evita a fragmentação social que 
alimenta a violência e o crime organizado (COLIGAÇÃO LULA PRESIDENTE, 2002, p. 15).

Ao analisar os planos do governo Lula, Félix (2012) afirma que observa-se a associação da educação ao desenvolvimento do mercado de trabalho e à competitividade internacional. Dessa forma, o primeiro mandato não foi marcado por grandes alterações na área da educação. Entretanto, no segundo mandato, as discussões referentes à gestão democrática iniciam-se e destaca-se o compromisso em:

Democratizar a Gestão Educacional, incentivando a reorganização e o aperfeiçoamento dos conselhos escolares e dos conselhos de cada um dos sistemas. Instituir o Fórum Nacional de Educação e convocar a I Conferência Nacional de Educação para avaliação das determinações da LDB, das metas do Plano Nacional e para aperfeiçoar o regime de cooperação entre as esferas de governo (LULA PRESIDENTEPROGRAMA DE GOVERNO 2007/2010, s/d, p. 17).

Ao comentar sobre o documento, Félix (2012) esclarece as propostas de ação do governo Lula para promover a participação das comunidades e para efetivar a gestão democrática, com ampliação da autonomia das unidades escolares nos processos de gestão pedagógica, administrativa e financeira.

Para entrar em acordo com as diretrizes do governo, o MEC deu início à formulação e ao desenvolvimento de programas com vistas à "[...] indução da gestão democrática à descentralização administrativa e à ampliação da participação da comunidade escolar na gestão e controle social das políticas educacionais" (FÉLIX, 2012, p.148).

Esses programas sob a coordenação da Secretaria de Educação Básica SEB/ MEC contemplaram diversas ações, entre elas, a:

Formação continuada dos diretores escolares,[...] programa "Escola de Gestores da Educação Básica"; Qualificação da atuação de gestores e técnicos das secretarias municipais de educação e representantes da sociedade civil,[...] por meio do Programa Nacional de Capacitação de Conselheiros Municipais de Educação (Pró-Conselho);Formação à distância,[...] realizada a partir do Curso Técnico de Formação para os Funcionários da Educação (Profuncionário); Desenvolvimento e 
implantação de ferramentas gerenciais [...]por meio do Plano de Desenvolvimento da Escola (PDE-Escola); Apoio aos dirigentes para [...]alcance das metas e compromissos do Plano Nacional de Educação (PNE), Lei no 10.172/01, e do Plano de Desenvolvimento da Educação (PDE) por meio do Programa de Apoio aos Dirigentes Municipais de Educação (PRADIME);Desenvolvimento de ações [...] por meio do Programa de Fortalecimento Institucional das Secretarias Municipais de Educação do Semiárido (PROFORTI); Desenvolvimento e implantação [...] Plano de Ações Articuladas (PAR). [...] Plano de Metas Compromisso Todos pela Educação e à elaboração do próprio PAR, orientado pelas metas de melhoria do Índice de Desenvolvimento da Educação Básica (IDEB); Chamado à sociedade para o trabalho voluntário de mobilização das famílias e da comunidade pela melhoria da qualidade da educação brasileira por meio do Plano de Mobilização Social pela Educação (PMSE);Promoção, em parceria com os sistemas de ensino, da participação das comunidades escolar e local na gestão administrativa, financeira e pedagógica das escolas públicas por meio do Programa Nacional de Fortalecimento dos Conselhos Escolares (PNFCE) (FÉLIX, 2012, p.148).

Essas ações aparentam estar interligadas aos princípios da participação, da democratização e da qualidade na gestão da escola pública, entretanto, sofreram críticas devido ao fato de o governo Lula dar sequência a programas do governo anterior, de Fernando Henrique Cardoso, como o Fundo de Desenvolvimento da Escola (FUNDESCOLA) instituído em 1997, que introduziu, nas escolas públicas, uma gestão baseada no modelo empresarial e se materializou por meio do Plano de Desenvolvimento da Escola (PDE), lançado pelo governo federal em 2007, o qual tem por estrutura princípios de gestão firmadas na qualidade total, na eficiência, na eficácia e na racionalização (FÉLIX, 2012).

Dessa forma, as ações desse período com vistas ao fortalecimento e à democratização da educação por meio do PNFCE, apresentaram-se como um programa de apoio integrado aos sistemas do PDE e do PAR. Tais ações, de forma contraditória, estão alinhadas à reforma do Estado dos anos de 1990, principalmente no que se refere à descentralização de sua execução (FÉLIX, 2012).

Dourado (2007) ao dissertar sobre programas federais na área da gestão escolar do governo Lula aponta que muitos foram implantados tendo por objetivo contribuir para o processo de democratização da escola, entretanto, no campo da gestão, alguns programas traduzem um movimento ambíguo, como o PDE e o PNFCE. 
O autor enfatiza que o PDE busca a melhoria da educação por meio de parâmetros de mercado e relaciona que "[...] Tal concepção alicerça-se numa ressignificação da gestão democrática e da participação, entendidas a partir da criação de canais de efetiva participação e decisão coletivas [...]" (DOURADO, 2007, p. 931).

\section{Implementação do Programa Nacional de Fortalecimento do Conselho Escolar em Cascavel - PR}

O PNFCE completou dez anos de lançamento em 2014 e foi inserido no município de Cascavel - PR no ano de 2012 e está atrelado a diversos programas do governo Lula como já apontamos. O programa foi estruturado no município de Cascavel por meio de processos de formação continuada, desenvolvidos com a realização de seminários e pela oferta de curso de formação presenciais e pela modalidade de educação à distância, a princípio para os técnicos da Secretaria de Educação do município e dos conselheiros escolares.

Todo o processo teve início com a participação da coordenadora em Seminário Nacional do Conselho Escolar, como representante da cidade de Cascavel. A coordenadora esclareceu que a cidade de Cascavel - PR chamou a atenção do MEC por ser considerada uma cidade polo de grande influência no oeste do Paraná e por estar em atraso no que se refere à gestão democrática das escolas municipais, ou seja, em atraso com a implementação do Conselho Escolar.

Nesse sentido, de acordo com a entrevistada houve uma pressão muito grande por parte do Ministério da Educação (MEC), pois em Cascavel - PR não havia sido instituído os Conselhos Escolares. A princípio a prioridade foi na criação do Conselho Municipal de Educação ${ }^{7}$ com seu fim específico.

A coordenadora do setor de Gestão Educacional da Secretaria Municipal de Educação nos informou que, em Cascavel - PR, no ano de 2003, houve uma tentativa de desenvolver o processo de implantação do colegiado, mas que não teve sequência apesar da movimentação ter

\footnotetext{
${ }^{7}$ O Conselho Municipal de Educação de Cascavel - CME/Cascavel foi criado pela Lei Municipal no 5.694/2010, é um órgão colegiado representativo da comunidade e da sociedade civil organizada, mediador entre a sociedade civil e o Poder Público, com a competência normativa e funções consultiva, deliberativa, fiscalizadora e de controle social. Iniciou suas atividades em abril de 2011.
} 
se iniciado em uma escola por meio da equipe pedagógica. As ações estão registradas em ata e, por meio de entrevista, a diretora que exercia o cargo no período, informou que não houve apoio da Secretaria de Educação do município, motivo pelo qual a implementação do Conselho Escolar não teve sequência, ou seja, faltou incentivo e apoio da instituição mantenedora.

No ano de 2012 foi nomeada a Comissão de Estudos e a Implantação dos Conselhos Escolares, por meio da Portaria $n^{\circ}$ 04/2012. Essa comissão foi composta por representantes da Secretaria Municipal de Educação; por representantes dos Diretores (as) das Escolas Municipais; por representantes dos Coordenadores (as) Administrativo Pedagógico dos Centros de Educação Infantil; por representantes dos Coordenadores Pedagógicos; por representantes dos Professores da Educação Básica Pública Municipal; por representantes das Associações de Pais Professores e Servidores; pelo Conselho Municipal de Educação; pelo Conselho de Acompanhamento e Controle Social do FUNDEB.

No mês de junho e julho de 2012 foram realizados trabalhos da Comissão e, em setembro, foi publicada a Lei $n^{\circ} 6.116$ de 11/09/2012. Conforme a Lei, os Conselhos tem a finalidade de "[...] efetivar a gestão democrática, atuando como mediador dos anseios da comunidade escolar, buscando alternativas para efetivar as políticas educacionais que visam garantir o cumprimento da função de educar e cuidar" (CASCAVEL, 2012, s/p).

Art. $2^{\circ}$ O Conselho Escolar é um órgão colegiado permanente de debate e articulação entre os vários segmentos da comunidade escolar, tendo em vista a gestão democrática do ensino público e a melhoria da qualidade do ensino. Art. $3^{\circ} \mathrm{O}$ Conselho Escolar exercerá as funções deliberativa, consultiva, fiscalizadora e mobilizadora, nos assuntos referentes à gestão pedagógica, administrativa e financeira da unidade escolar, resguardados os princípios constitucionais, as disposições legais e as diretrizes da política educacional da Secretaria Municipal de Educação. Art. $5^{\mathbf{0}}$ As funções do Conselho Escolar são: I Deliberativas: Decidir sobre o Projeto Político-Pedagógico, aprovar encaminhamentos de problemas, garantir a elaboração de normas internas e o cumprimento de legislação vigente, sobre a organização e o funcionamento da instituição, propondo à direção escolar as ações a serem desenvolvidas; II - Consultivas: Assegurar e analisar as questões encaminhadas pelos diversos segmentos da instituição e apresentar sugestões ou soluções, que poderão ou não ser acatadas pela direção; III - Fiscalizadoras: Acompanhar a execução das ações pedagógicas, administrativas e financeiras, avaliando e garantindo o cumprimento das normas da instituição e a qualidade da educação; V - Mobilizadoras: 
promover a participação, de forma integrada, dos segmentos representativos da comunidade escolar, contribuindo assim para a efetivação da democracia participativa (CASCAVEL, 2012, s/p).

De acordo com nosso entendimento, o Conselho Escolar pode ser um instrumento que privilegia a participação da comunidade escolar na gestão da escola, dentro dos limites da sociedade capitalista.

\section{O Conselho Escolar no Município de Cascavel na percepção de alguns de seus membros}

Nesse momento o artigo apresenta o resultado da pesquisa de campo desenvolvida por meio de questionários, observações e entrevistas. Após análise de material pudemos compreender que há certa contradição referente à reflexão sobre a categoria participação.

É preciso considerar que a participação sofre efeitos de "concepções e crenças sedimentadas historicamente na personalidade de cada pessoa e que movem suas práticas e comportamentos no relacionamento com os outros" (PARO, 2000, p. 43). Da mesma forma, observar o "modo de pensar e agir das pessoas que aí atuam facilita/incentiva ou dificulta/impede a participação dos usuários" (PARO, 2000, p. 43).

O resultado da pesquisa revelou que a concepção dos diretores sobre participação está de acordo com o que a lei municipal estabelece, o que observamos ao longo do trabalho é que o termo gestão democrática, bem como autonomia, descentralização, participação são categorias que são interpretadas de formas variadas conforme a concepção política, histórica, social de cada indivíduo, ou por aquilo que é construído ideologicamente para legitimar essa política.

Com a abertura das escolas para a participação da comunidade, via Conselho Escolar, estão atreladas diversas dificuldades, inclusive de uma cultura de não participação. Paro (2000) esclarece que, em geral, os pais argumentam sobre a participação apenas na execução de tarefas ou na contribuição financeira. A esse respeito concordamos com o autor, conforme observação em reuniões e em cursos de formação na qual participamos como campo de pesquisa.

Com a nova concepção de administração, o papel do diretor/gestor na escola assumiu uma nova característica: coordenar um colegiado no processo de participação da comunidade, 
representando maior diversidade de relacionamentos dentro dessa comunidade, que envolvem princípios que vão além de cooperação e de sugestões para a solução de problemas.

O envolvimento da comunidade escolar passa a ser considerada primordial para uma boa administração, assim quando a falta de participação ocorre, passa a ser um problema, principalmente quando diretores precisam "caçar a laço" um integrante da comunidade. Nesse sentido, conforme observamos na pesquisa de campo, os diretores apontam como a maior dificuldade o envolvimento dos pais ou dos responsáveis no Conselho Escolar.

Dessa forma, compreendemos que, na percepção da maioria dos diretores que responderam os questionários, o Conselho Escolar possui dificuldades em sua implementação devido à falta de envolvimento da família na escola.

Nessa perspectiva, recai sobre a família o limite de uma gestão democrática via Conselho Escolar. Entendemos que a democratização da gestão escolar só será possível com a democratização da sociedade.

Compreendemos que a implementação do Conselho Escolar em Cascavel - PR ainda está em processo de adaptação e que diversas dificuldades ocorrem, o que não se pode perder de vista é que o colegiado do Conselho Escolar é a abertura de um espaço para no mínimo o diálogo. Isso é necessário, principalmente, para que a família conheça os seus direitos a uma educação de qualidade e para não deixar cair no esquecimento a luta por esse direito e, ao mesmo tempo, não se torne um colegiado só para legitimar propostas decididas em outras instâncias.

De modo geral, a compreensão dos segmentos que compõem o Conselho Escolar indica que o colegiado é um órgão com o objetivo de auxiliar na melhoria da escola. Os conselheiros percebem o Conselho Escolar como um espaço para estimular o envolvimento da comunidade escolar na realização de tarefas na arrecadação de verbas, na discussão de problemas sociais e na legitimação das decisões tomadas previamente, outro ponto que fora apontado é o limite da ação do colegiado, tendo em vista que esbarra em leis engessadas.

\section{Considerações Finais}

Após estudo e análise dos dados coletados em pesquisa de campo, consideramos que a política educacional que estimula a gestão democrática por meio de um colegiado que é o Conselho Escolar, está firmado em bases de orientações advindas de organismos internacionais 
que materializou-se no PNFCE cujo objetivo principal é de fortalecer os Conselhos Escolares e de mobilizar a sua criação e desenvolvimento.

O Conselho Escolar é uma instância colegiada, propalada pelo PNFCE, como um órgão máximo para a tomada das decisões realizadas dentro da instituição de ensino.

Acima de tudo é fundamental ressaltar que o Conselho Escolar foi implementado no município de Cascavel por meio de instâncias superiores, instituído por um programa na esfera federal, ou seja, não foi resultado de um movimento que emergiu da sociedade. Pelo contrário, no momento em que houve uma tentativa de implementação que partiu da classe dos educadores, a experiência não teve continuidade, tendo em vista que, devido à falta de suporte, não houve sequência no desenvolvimento do colegiado.

O Conselho Escolar em Cascavel ainda anda em descompasso entre as partes envolvidas, visto que, por meio do resultado da pesquisa de campo, foi possível verificar que, em geral, a participação é um tema ainda polêmico, pois a direção da escola revela a preocupação com a falta do envolvimento da comunidade escolar, em especial, dos pais. Enquanto que os conselheiros, do segmento dos pais, compreendem a importância do seu envolvimento, entretanto, não encontram sentido em uma participação limitada devido à legislação.

Dessa forma, inicia-se uma desmotivação que reflete na falta de participação, fato que já está ocorrendo mesmo em um espaço curto de tempo da implementação do Conselho Escolar.

Nesse sentido, apesar de estarmos entrando na era da participação, esse tema ainda parece desconhecido e o "interesse pela participação não parece estar acompanhado de um conhecimento generalizado do que ela é de seus graus e níveis de suas condições e suas ferramentas operativas" (BORDENAVE, 1994, p. 9).

Não se pretende questionar o valor da participação da comunidade na gestão da escola, entretanto, limitar o sucesso do processo democrático a somente esse item é, no mínimo, cometer um equívoco, visto que o Conselho Escolar, como um instrumento no processo democrático, está carregado da ideologia capitalista.

Dessa forma, entendemos que o Conselho Escolar possui limitações em suas ações que precisam ser discutidas, analisadas e compreendidas por aqueles que fazem parte do Conselho Escolar, bem como toda a sociedade que anseia por uma educação que favoreça o aluno, para que possam avaliar os limites de sua participação na gestão da escola. 
Compreendemos que o limite das ações do Conselho Escolar não é do município de Cascavel, mas sim da sociedade capitalista. Assim, nesses termos, concluímos que à democracia que se consolidou foi concedida, uma estratégia política para amenizar os conflitos, resultando em uma participação que não avança, e é restrita, o que acaba por legitimar a estrutura hierárquica carregada de ideologia burocrática que não é rompida. Ao contrário, é como uma teia que prende as possibilidades de uma participação real na tomada de decisão dos rumos da escola.

O Conselho Escolar pode indicar uma possibilidade de avançar em um espaço dentro da escola. Fato é que, dentro de uma contradição, podemos concluir que a não participação da comunidade escolar acaba se tornando um ganho, visto que a efetivação do Conselho Escolar, nesses moldes, significa um total recuo do Estado.

\section{Referências:}

ANTUNES, A. Aceita um conselho? Como organizar o colegiado escolar. São Paulo: Cortez, 2002.

ARANDA, M.A.M. O significado do princípio da participação na política educacional brasileira nos anos iniciais do século XXI: o declarado no PPA —Brasil de Todos (2004 2007)\|. Tese (Doutorado em Educação). Universidade Federal do Mato Grosso do Sul. Campo Grande, MS. 2009.

BOBBIO, N.; METTEUCCI, N.; PASQUINO, G. Dicionário de Política I. Trad. Carmen C. Varriale et al.; coord. trad. João Ferreira; rev. geral João Ferreira e Luis Guerreiro Pinto Cacais. 1. ed. Brasília: Editora Universidade de Brasília, 1998.

O futuro da democracia. São Paulo: Paz e Terra, 2000.

BORDENAVE, J. E. D. O que é Participação. 8. ed. São Paulo: Brasiliense, 1994.

BRASIL. Constituição Federal de 1988. Disponível em:

http://bd.camara.gov.br/bd/bitstream/handle/bdcamara/15880/Constituicao_federal_Brasil_40e d.pdf. Acesso em: 13 jan. 2014.

Emenda Constitucional no ${ }^{\circ}$, de 12 de setembro de 1996. Disponível em: http://www.planalto.gov.br/ccivil_03/constituicao/emendas/emc/emc14.htm. Acesso em: 14 jan. 2014. 
Senado Federal. Lei de Diretrizes e Bases da Educação Nacional: no 9394/1996.

Brasília, DF. Estabelece diretrizes e bases da educação nacional. Disponível em:

http://www.planalto.gov.br/ccivil_03/leis/19394.htm. Acesso em: 13 jan. 2014. 169

. Ministério da Educação. Secretaria de Educação Básica. Conselhos escolares:

democratização da escola e construção da cidadania. Elaboração Ignez Pinto Navarro et al. Brasília: MEC, SEB, 2004.

Ministério da Educação. Portaria no 2.896, de 17 de setembro de 2004. Cria o Programa Nacional de Fortalecimento de Conselhos Escolares. Diário Oficial da União, Brasília - DF, nº 180. Seção 2, p. 7.

. Ministério da Educação Secretaria de Educação Básica - Conselhos Escolares: Uma estratégia de gestão democrática da educação pública. Programa Nacional de Fortalecimento dos Conselhos Escolares - Caderno 1. Brasília - DF: MEC, SEB, 2004.

CASCAVEL, Secretaria Municipal de Educação. Plano Municipal de Educação. 2004. Disponível em:

http://www.cascavel.pr.gov.br/arquivos/semed/plano_municipal_de_educacao/plano.htm. Acesso em: 26 jan. 2014. 171

Secretaria Municipal de Educação. Lei no 6.116/2012. Disponível em:

https://camaracascavel.pr.gov.br/leis-municipais.html?sdetail=1\&leis_id=6402. Acesso em: 28 jan. 2014.

CUNHA, L. A. A educação na nova constituição. Revista da Associação Nacional de Educação, ano 6, n. 12. São Paulo, 1987.

. Educação, Estado e democracia no Brasil. São Paulo: Cortez,1991.

CURY, C. R. J. Os Conselhos de Educação e a gestão dos sistemas. In: FERREIRA, N. S. C.; AGUIAR, M. A. (Orgs.). Gestão da educação: impasses, perspectivas e compromissos. São Paulo: Cortez, 2000.

DOURADO, L. F. Políticas e gestão da educação básica no Brasil: limites e perspectivas. Educação e Sociedade, Campinas, v. 28, n. 100, p. 921-946, out., 2007.

FÉLIX, R. G. Políticas de gestão educacional no Brasil: o Programa Nacional de Fortalecimento dos Conselhos Escolares (2004-2010). Tese (Doutorado em Educação). Universidade Federal de Mato Grosso do Sul - UFMS. Mato Grosso do Sul, 2012.

GRACINDO, R. V. O gestor escolar e as demandas da gestão democrática: Exigências, práticas, perfil e formação. Revista Retratos da Escola, Brasília, v. 3, n. 4, p. 135-147, jan./jun. 2009.

2007.

Gestão democrática nos sistemas e na escola. Brasília: Universidade de Brasília, 
GOHN, M. G. M. Movimentos Sociais e Educação. 5. ed. São Paulo: Cortez, 2002.

LIMA, A. B. Políticas Educacionais e o Processo de —Democratizaçãoll da Gestão Educacional In: LIMA, A. B. (Org.) Estado, políticas educacionais e gestão compartilhada. São Paulo: Xamã, 2004.

LÜCK, H. Concepções e processos democráticos de gestão educacional. 4. ed. Petrópolis, RJ: Vozes, 2009. 173

PARO,V.H. Escritos sobre Educação. São Paulo: Xamã, 2001. 174

RAMOS, G. P.; FERNANDES, M. C. Lutas, contradições e conflitos: a construção histórica do conselho escolar no Brasil. In: LUIZ, M. C. (Org.) Conselho Escolar: Algumas concepções e propostas de ação. São Paulo: Xamã, 2010.

WERLE, F.O.C. Conselhos Escolares: implicações na gestão da Escola Básica. Rio Janeiro: DP\&A, 2003. 